\title{
BMJ Open Parents' preferences for follow-up care in a type 1 diabetes paediatric population: a survey-based study in Quebec, Canada
}

\author{
Maude Laberge (D) , ${ }^{1,2}$ Monia Rekik, ${ }^{1}$ Kodjo Mawuegnigan Djiffa ${ }^{1}$
}

To cite: Laberge M, Rekik M, Djiffa KM. Parents' preferences for follow-up care in a type 1 diabetes paediatric population: a survey-based study in Quebec, Canada. BMJ Open 2021;11:e046757. doi:10.1136/ bmjopen-2020-046757

- Prepublication history and additional supplemental material for this paper are available online. To view these files, please visit the journal online (http://dx.doi.org/10.1136/ bmjopen-2020-046757)

Received 09 November 2020 Accepted 19 October 202
A) Check for updates

(c) Author(s) (or their employer(s)) 2021. Re-use permitted under CC BY-NC. No commercial re-use. See rights and permissions. Published by BMJ.

${ }^{1}$ Operations and Decision Systems, Universite Laval Faculte des sciences de I'administration, Quebec, Quebec, Canada

${ }^{2}$ Centre de recherche du CHU de Québec-Université Laval, Quebec, Quebec, Canada

Correspondence to Dr Maude Laberge; maude.laberge@fsa.ulaval.ca

\section{ABSTRACT}

Objectives Examine variations in parent's preferences for their child's type 1 diabetes (T1D) follow-up care and the determinants of the preferred intensity of care. Clinical guidelines recommend multidisciplinary management of T1D, with follow-up visits with an endocrinologist at least every 3 months in the paediatric population. However, there could be heterogeneity in parents' needs, and preferences in terms of care management may deviate from clinical guidelines.

Setting Not applicable.

Participants Parents who have a child living with T1D and who reside in Quebec, Canada.

Intervention In collaboration with a patient-partner (a parent of a child with T1D), we developed a survey to collect data from parents of children living with T1D. Our primary outcome of interest was the preferred time in months between two appointments. We ran a probit model to analyse longer time (over 3 months between appointments), compared with the standard of care (3 months or less).

Results Results suggest that about one-third (33\%) of parents want to deviate from the guideline. Parents who want to increase the time between appointments are more experienced in the management of the disease and have higher costs than those who wish to follow the 3-month guideline. The number of years since the diagnosis is positively associated with a preference for a longer time between appointments, while the perceived useful of information provided during the consultation, and a parent having made a change in their professional life were negatively associated with a desire to space out appointments. The child's gender is not a significant factor in parents' preferences.

Conclusions Adapting visit protocols could make the health system more efficient to respond to T1D patients and their parent's needs.

\section{INTRODUCTION}

Type 1 diabetes (T1D) is usually diagnosed in childhood and the diagnosis is generally a disruptor for the family. ${ }^{1}$ It requires changes in lifestyle and habits, particularly in terms of food and eating schedules, ${ }^{2}$ and regular medical visits. Clinical guidelines recommend multidisciplinary management of T1D,
Strengths and limitations of this study

- A patient-partner was engaged in all steps of the study.

- Clinical guidelines may lead to overutilisation of services for the follow-up of type 1 diabetes in a paediatric population.

- Clinical guidelines may not be possible to follow in areas with limited access to services (eg, rural and remote)

with follow-up visits with an endocrinologist at least every 3 months in the paediatric population. ${ }^{3}$

Clinical guidelines are important in standardising care and their development represented a shift in paradigm away from professional judgement. The past 35 years have seen an increasing development of clinical guidelines to manage quality of care, particularly for the management of chronic conditions. ${ }^{45}$ The development includes the participation of experts and a review of the literature to determine which treatments are most effective. However, they are based on average effects ${ }^{6}$ and there have been reports of conflict of interests in expert panels. ${ }^{78}$ In addition, the development process does not necessarily involve patients, whose preferences may not be reflected in clinical guidelines ${ }^{9}$ and these may even be in conflict with guidelines. ${ }^{10}$ Clinicians' perspective may be focused on the potential clinical benefits, without acknowledging the costs for patients. Patients may not be comfortable expressing concerns over the cost of proposed treatments, but research findings suggest that they would like their doctors to bring up the issue. ${ }^{11}$ While there is a growing utilisation of decision aids to support shared decision making, cost information is scarce in the aids. $^{12}$ 
In the case of paediatric T1D, the condition affects not only children, but also their parents, who may feel emotionally distressed, ${ }^{13}{ }^{14}$ and may need to make changes to their professional situation in order to care for their child. ${ }^{15}$

In such a context, regular follow-up visits every 3 months may not reflect the preferences of parents, and yet endocrinologists following clinical guidelines schedule them as recommended. Some studies examined other aspects of T1D care management, but the frequency of such visits and how this frequency aligns with parents' preferences has not yet been studied. In our sample for instance, the preferences of almost one third of parents (33.08\%) diverge from the recommended time between the last two follow-up visits. We hypothesise that there is heterogeneity in the costs and benefits of such visits and that parents' needs and preferences in terms of care management may deviate from the guideline.

\section{METHODS}

The methods of the study are described in detail in the protocol. ${ }^{16}$ Briefly, in collaboration with a patient-partner (a parent of a child with T1D), we developed a survey (see online supplemental appendix) to collect data from parents of children living with T1D in Quebec, the second most populous province of Canada. The survey was reviewed by two parents of children living with diabetes and a physician for face validity, which led to slight modifications in the language. Participants were recruited with posters in diabetes clinics, on social media, through T1D associations and fundraising events, and personal contacts of the research team members. The questionnaire was made available online in both French and English and was anonymous.

\section{Patient and public involvement}

A patient-partner (parent of a child living with diabetes) contacted the lead author about conducting a study on follow-up care with concerns about how standardised practices may not meet the needs of all parents. The patient-partner and the researcher had a meeting to discuss potential research questions and a study design. Once elaborated, the patient-partner facilitated the recruitment of participants through connections with associations and to other parents of children living with T1D. A research assistant followed up with the distribution of the recruitment material (posters for clinics, flyers to distribute at events, etc). Participants were informed that no personal identifiers or contact information would be collected in the process. However, the research team plans to disseminate the study results to the diabetes associations that supported participant recruitment, once these results are published. An open access publication also enables sharing the link to the article on social media platforms through which participants were recruited, among others.

\section{Variables}

Our outcome variable of interest was the participant's response to their preferred time laps between two follow-up visits in months, which in the questionnaire could be answered with a cursor or by writing a number $(\mathrm{eg}, 6)$.

We were interested in examining to which extent parents' preferences with follow-up visits align with the clinical guidelines and in estimating the effect of perceived costs and benefits of the visits on the preferred frequency of visits. Costs considered were those related to the visits (such as transportation or parking). Participants reported their estimated cost of a visit (in Canadian dollars). Another question asked parents if they had made a change in their professional life because of the child's diagnosis: for a job that offered more flexibility, to reduce the number of hours of work, or to leave the workforce entirely. We measured benefits indirectly through the perceived value of the information gained during the follow-up appointment. We accounted for whether the child used an insulin pump, the experience with the condition in terms of years since the diagnosis, and the region of residence as some regions have specialised multidisciplinary teams for paediatric diabetes.

\section{Analytical approach}

Although the question regarding the period that should separate two appointments let respondents put an actual number of months, our interest was in the deviance to the clinical guideline. Therefore, we decided to transform the outcome into a two-level variable as follow:

$$
\mathrm{y}==\left\{\begin{array}{l}
0 \text { if } z \leq 3 \\
1 \text { if } z>3
\end{array}\right.
$$

where $z$ represents the number of months between two appointments with the endocrinologist from the parents' perspective. The first category $(y=0)$ includes number of months up to three, that is, reflecting the current guideline. This group is considered as our benchmark and serves as the comparison group. The other group ( $y=1$ ) represents parents willing to deviate from the current guideline by increasing the time (in months) that separate two visits with the endocrinologist (ie, 4 months or more).

A typical approach to analyse a binary variable such as our outcome $y$ is to estimate a probit or logit model. We rely on a probit model in the framework of this paper. Hence, we model the effect of our control variables on the willingness of parents to lengthen the time between two appointments with the endocrinologist to over 3 months $(y=1)$.

For a typical parent $i$, our model is as follow:

$$
p\left(y_{i}=1\right)=F\left(\beta X_{i}\right)
$$

where $X_{i}$ is a vector of explanatory variables, $\beta_{k}$ the parameter vector and $F($.$) is the cumulative distribution$ function of a standard normal distribution. 


\begin{tabular}{lll}
\hline \multicolumn{2}{l}{ Table 1} & \multicolumn{2}{l}{ Descriptive statistics of the study } & population \\
\hline & $\mathbf{y = 0}$ & $\mathbf{y = 1}$ \\
\hline Sample proportion & 66.92 & 33.08 \\
$\begin{array}{l}\text { No of years since } \\
\text { diagnosis (SD) }\end{array}$ & 4.23 & 5.72 \\
$\begin{array}{l}\text { Direct cost to attend an } \\
\text { appointment in \$C100 }\end{array}$ & 1.69 & $(4.00)$ \\
(SD) & $(3.02)$ & 2.77 \\
\end{tabular}

Use of insulin pump

\begin{tabular}{|c|c|c|}
\hline Yes & 36.93 & 45.98 \\
\hline No & 63.07 & 54.02 \\
\hline \multicolumn{3}{|l|}{$\begin{array}{l}\text { Helpfulness of information } \\
\text { provided }\end{array}$} \\
\hline No/minor improvements & 13.13 & 28.38 \\
\hline $\begin{array}{l}\text { Yes, noticeable } \\
\text { improvements }\end{array}$ & 47.50 & 48.65 \\
\hline $\begin{array}{l}\text { Yes, great } \\
\text { improvements }\end{array}$ & 39.38 & 22.97 \\
\hline \multicolumn{3}{|l|}{$\begin{array}{l}\text { Change in professional life } \\
\text { (1or both parents) }\end{array}$} \\
\hline Yes & 43.90 & 47.37 \\
\hline No & 56.10 & 52.63 \\
\hline \multicolumn{3}{|l|}{ Region } \\
\hline $\begin{array}{l}\text { Capitale nationale and } \\
\text { Chaudière-Appalaches }\end{array}$ & 36.93 & 32.18 \\
\hline $\begin{array}{l}\text { Montréal and } \\
\text { Montérégie }\end{array}$ & 27.27 & 16.09 \\
\hline Other regions & 35.80 & 51.72 \\
\hline \multicolumn{3}{|l|}{ No of children } \\
\hline One & 18.18 & 25.00 \\
\hline Two & 55.84 & 50.86 \\
\hline More than two & 25.97 & 24.14 \\
\hline
\end{tabular}

\section{RESULTS}

We report descriptive statistics in table 1. Although we had 311 respondents $(\mathrm{n}=23$ to the English version and $n=288$ to the French version), some respondents skipped questions which reduced the number of observations that could be used in our analyses. Results suggest that the preferences of almost one third of parents $(33.08 \%)$ deviate from the guideline. Parents willing to lengthen the time between two appointments are more experienced in the management of the disease and have disbursed, on average, more than parents in the first category.

We report the result of our models in table 2. A positive coefficient means that an increase in the predictor leads to an increase in the predicted probability of preferring more space-out appointments. A negative coefficient means that an increase in the predictor leads to a decrease in the predicted probability. The pseudo $R^{2}$ indicates that the model explains $18.71 \%$ of the variation. The significance test suggests that our covariables
Table 2 Factors affecting parents' preferences in shortening or lengthening time between follow-up visits

\section{Variables}

\begin{tabular}{ll}
\hline No of years since diagnosis & $0.105^{\star \star \star}$ \\
& $(0.0260)$ \\
Average cost of an appointment & 0.0198 \\
& $(0.0151)$ \\
Child uses an insulin pomp & -0.377 \\
& $(0.225)$
\end{tabular}

Helpfulness of information provided:

\begin{tabular}{cl} 
No change or minor improvement & Reference \\
Yes, noticeable improvements & $-0.603^{\star}$ \\
& $(0.265)$ \\
Yes, great improvements & $-1.06^{\star \star *}$ \\
& $(0.300)$ \\
At least one parent made a change in & $-0.576^{\star \star}$ \\
their professional life & $(0.204)$ \\
Region & \\
Capitale nationale and Chaudière & -0.326 \\
Appalaches & $(0.221)$ \\
Montréal and Montérégie & $-0.572^{\star}$ \\
& $(0.276)$ \\
Other & Reference \\
No of kids & \\
One kid & $0.709^{\star *}$ \\
& $(0.234)$ \\
Two kids & Reference \\
More than two kids & -0.0312 \\
& $(0.246)$ \\
Constant & 0.440 \\
& $(0.292)$ \\
\hline Pseudo & 0.1871 \\
Observations & 224 \\
\hline
\end{tabular}

${ }^{\star} \mathrm{P}<0.05,{ }^{* \star} \mathrm{p}<0.01,{ }^{* \star *} \mathrm{p}<0.001$

SEs in parentheses.

are jointly significant at $1 \%$. A one unit increase in the number of years since the T1D was diagnosed raises the probability that a parent wants to increase the number of months between two appointments by 0.105 . The coefficient of the direct cost to attend an appointment is positive but not significant. A child's use of an insulin pump is associated with a lower (but not significant) likelihood of wanting to increase the number of months between two visits. The dummies related to the helpfulness of the information provided in the daily management of the child's diabetes are negative and significant. Parents who derive great and noticeable improvements from the information provided during their last appointment are more likely to want to follow the guideline compared with those for whom the information made no change or minor change. 

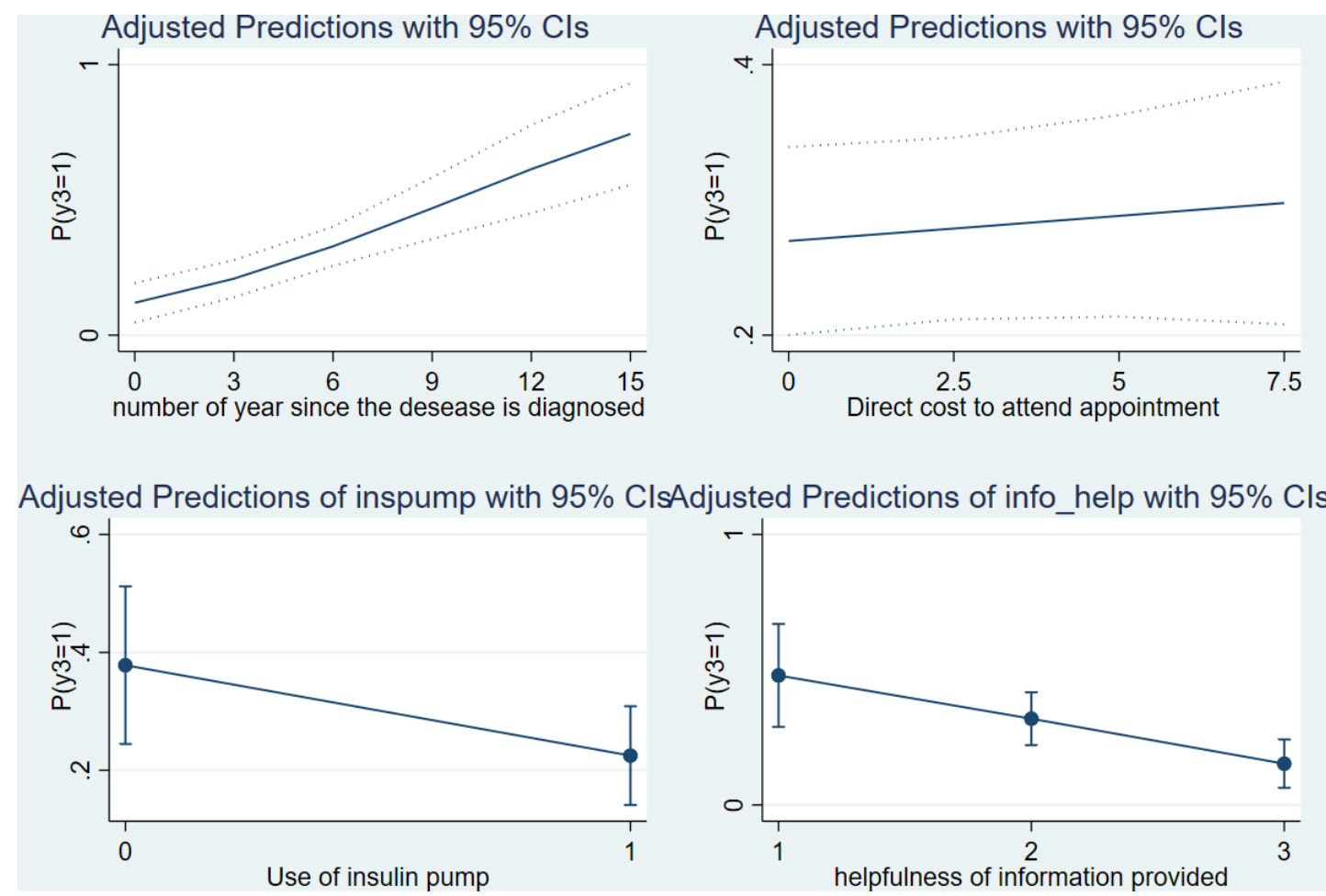

Figure 1 Adjusted predictions of covariates on probability of distancing visits the $y$-axis of each graphic represents the probability of preferring to distance visits over 3 months the $\mathrm{x}$-axis of each graphic represents a covariate (included in the regression models): number of years since the T1D was diagnosed, direct cost to attend appointments, use of insulin pump, helpfulness of information provided during the appointment, having made a change in their professional life (such as leaving a position for one that is more flexible or changing to part-time work), region where the family leaves, number of children in the family. T1D, type 1 diabetes.

The coefficient related to the dummy variable assessing whether parents have made changes to their professional life is negative and significant. This suggests that parents who have made changes to their professional life to accommodate their child's condition are less likely to want to increase the number of months between two appointments compared to those who have not made any change. The number of children in the family is also significant. Compared with parents with two children, parents with one child are more likely to want to increase the time between two appointments while those with more than two children are less likely. This suggest that having more children does not lead parents to want to space out visits with the endocrinologist with their child living with T1D. Variables such us the child's gender, parent's education level and income have no significant effect on our dependant variable.

Another useful way of assessing the relationship between independent variables and a binary outcome is by computing and plotting the predicted probabilities. These graphs provide a quick and informative way to picture the relation between a binary outcome and a covariable. To display our results, we plot the probabilities of event $y_{2}=1$ separately for our covariables. The graphs are presented in figures 1 and 2.

The probability that $(y=1)$ increases with the number of years since the T1D was diagnosed. The slope is steeper from 6 years of experience suggesting that the more experienced parents have a stronger preference toward increasing the distance between visits with the endocrinologist. The same pattern is observed with the direct cost to attend the appointment, but the slope is regular and lower. Parents living in a region with an easier access to a specialised T1D team (Capitale Nationale and Chaudière Appalaches and Montreal and Montérégie) are significantly less likely to want to increase the number of months between appointments. The region variable appears to represent the effect of the indirect cost variable such as the number of workdays missed, or the number of school days missed.

\section{DISCUSSION}

Several studies have investigated the impact of clinic visits on glycaemic control in T1D children and adults. ${ }^{17}$ The majority of the studies align with the current international treatment guidelines for young people with T1D, which recommend that a young person should attend a diabetes clinic four times per year, at 3-month intervals for a better glycaemic control. This control is generally determined by the value of HbAlc. Our study rather addresses the relevance of in-person clinic visits from the parents' perspectives. It reveals that the 3-month intervals do not necessarily meet all parents' preferences and needs. This discrepancy is explained by many factors related to the number of years since 
Adjusted Predictions of change_prof with 95\% CAdjusted Predictions of region2 with 95\% Cls
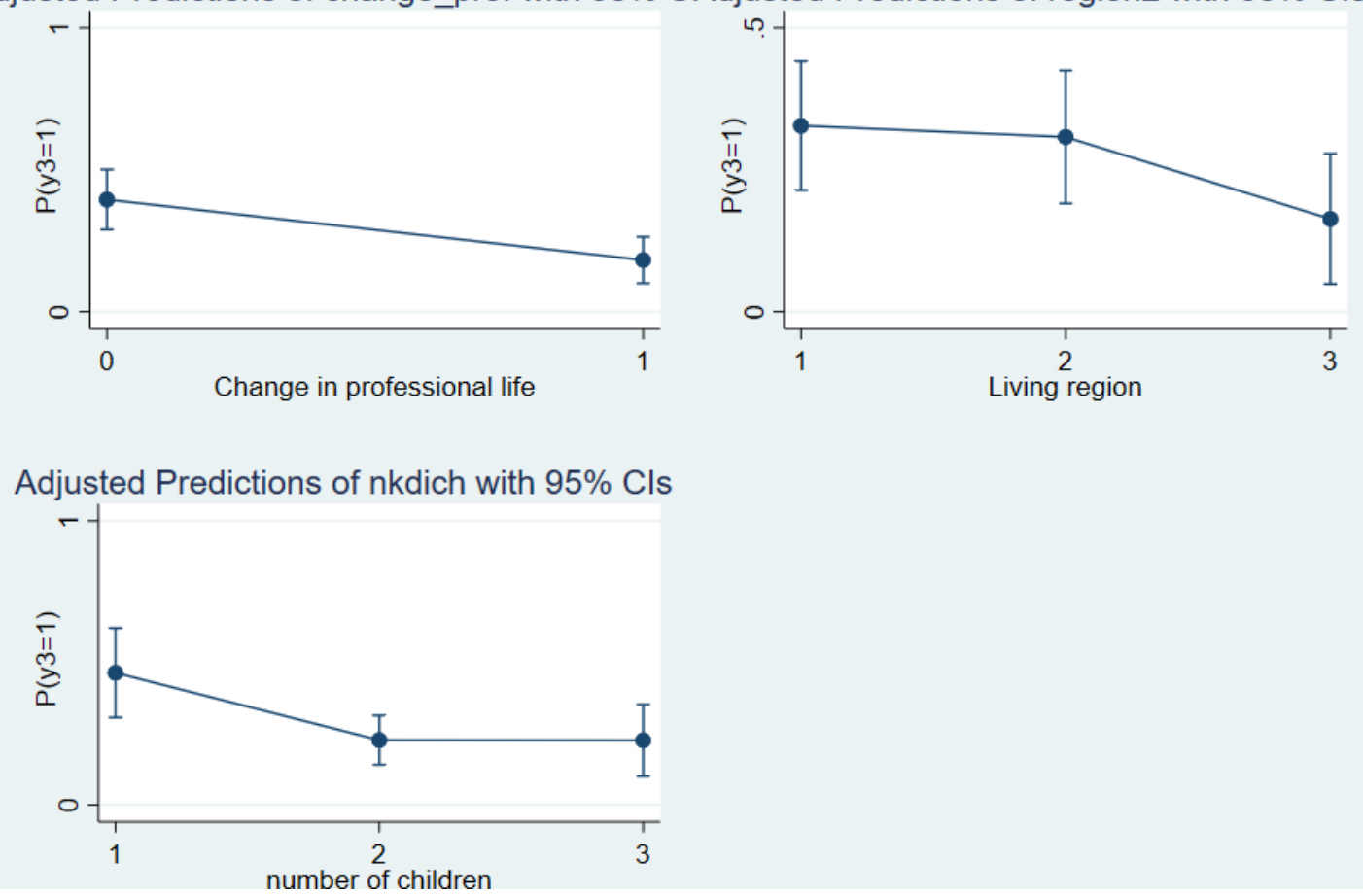

Figure 2 Adjusted predictions of covariates on probability of distancing visits. The y-axis of each graphical represents the probability of preferring to distance visits over 3 months the $\mathrm{x}$-axis of each graphic represents a covariate (included in the regression models): number of years since the T1D was diagnosed, direct cost to attend appointments, use of insulin pump, helpfulness of information provided during the appointment, having made a change in their professional life (such as leaving a position for one that is more flexible or changing to part-time work), region where the family leaves, number of children in the family. T1D, type 1 diabetes.

the diagnosis, the average cost of a visit for parents, the type of care (insulin pump or daily injections), the helpfulness of information provided during the visits, the impact on the parents' professional life and the region of residence. A prospective cohort study on 1472 T1D children and young adults living in British Columbia, Canada, reported a decrease in the adherence to clinical practice guidelines for the treatment of T1D across all age groups as years from diagnosis of T1D increases. ${ }^{18}$ Health region, sex and age at diagnosis emerged as important factors that impact adherence to clinical guidelines. Our results bring additional factors regarding the preferences of parents and the factors associated with those preferences. Adapting the time interval between visits to the patients' needs would align with the philosophy of putting patients and their caregivers (parents) at the centre of care. ${ }^{1920}$

Our results show that, as the number of years since the T1D diagnosis increases, parents prefer to space out visits to the endocrinologist. This can be explained by the fact that parents acquire over time the knowledge necessary for a better management of their children's diabetes. Previous studies pointed out the desire of parents to make most decisions, over time, independently or in collaboration with their care provider and to be respected for their expertise gained from the lived experience with diabetes. ${ }^{17} 2122$ Our hypothesis is further supported by our results showing that parents for whom the information provided during the last appointment had little or no effect on how they cared for their children's T1D prefer more spaced visits compared with parents who used the information to make changes. Our results may also indicate that the information provided during the visits may not be in line with parents' needs. In Howe et al, parents wanted clinicians to be knowledgeable and up to date in research and technology, and able to provide them with clear medical information and resources. ${ }^{21}$

Our study shows no significant correlation between the HbAlc value at the last appointment and the preferred time interval between visits suggesting that frequent visits are not necessarily seen by parents as a way of improving the daily management of diabetes. This supports the ideas already reported in other studies where interviewed parents (experienced and with a new diagnosis) insisted on the importance of immediate access to the diabetes team when needed for the problems encountered in their daily lives outside the routine scheduled visits. ${ }^{23}$ Recent studies also questioned blood glucose monitoring in the time interval between clinic appointments. ${ }^{18}$ Amed et al reported a significant decline in the number of blood glucose checks as the number of days increased from the clinic visit. ${ }^{18}$ Although this result may in part suggest the necessity of maintaining regular in-person visits to keep the patients motivated, other options could 
be considered to remedy this problem by resorting to alternative human (eg, psychologist) and technical resources. A number of papers raised this issue and examined the recourse to other care intervention types such as internet-based transmission and telemedicine to either replace in-person visits ${ }^{24}$ or to offer additional support to patients and parents between visits for a better diabetes control. ${ }^{25-27} \mathrm{~A}$ pilot study (with a limited number of patients and a single clinic) compared a 6 month intensive remote therapy intervention (IRT) with conventional care (CC) for children and adolescents with T1D. ${ }^{25}$ All patients (both IRT and CC) had regular quarterly clinic visits and uploaded device data regarding insulin, blood glucose and physical activity to the clinic on a weekly basis. For IRT patients, the data were analysed by research staff every week (diabetes educator, nurse practitioner and/or physician) and parents were contacted to discuss recommendations in case an adjustment to the diabetes management plan was required. The pilot study concludes that remote monitoring and between-visit patient interaction may be an effective strategy for improving diabetes control among children and adolescents with T1D. It reports that routine quarterly care for IRT participants yielded shorter clinic visits. Another study on T1D adolescents showed that electronic transmission of blood glucose levels and other diabetes data every 2 weeks-in lieu of a clinic visit-results in a similar level of glucose control and incidence of acute diabetes complications when compared with current standard care. ${ }^{24}$ Such care delivery models could reduce the costs to families associated with in-person visits, a cost that was associated with a preference for more spaced-out visits in our study. Another potential option would be to have virtual consultations, which would lower the costs for parents. Physicians in Quebec are mostly paid through fee-forservice. At the time that the survey was developed, physicians could only bill for in-person consultations. With the pandemic, billing was permitted for virtual consultations but only for the duration of the state of sanitary emergency. Physician payment policies would need to be modified to enable the use of virtual consultations postpandemic.

Our results question the relevance of in-person visits with an endocrinologist at the same frequency regardless of the patients' needs and preferences. One should also keep in mind that the use of telemedicine and related diabetes technology requires a minimal knowledge and could generate increasing costs for patients to acquire them, depending on the nature of the technology and insurance coverage. ${ }^{28}$

Our results also suggest that parents who have made changes to their professional life are less likely to want to increase the number of months between two appointments compared with those who have not made any change. Our interpretation is that this change was made by parents to accommodate their child's condition. This is supported by a recent study where job insecurity was reported by parents as a major barrier of good diabetes management in their child. ${ }^{29}$ Parents felt the length and timing of clinic visits could lead to a loss of pay or job. ${ }^{29}$

Our results also reveal that the use of an insulin pump is associated with a lower likelihood of wanting to increase the number of months between two visits. This can be explained by the challenges of learning and operating the pump, compared with multiple daily injections, that requires specific skills to master the technology. ${ }^{30}$ Some parents have more difficulty making choices among the multitude of options offered by insulin pumps to adjust the care plans by themselves.

Our findings also point out that patients who live far from specialised diabetes clinics prefer to increase the time between in-person visits. Our interpretation is that these parents will have to be away from work and their children from their schools longer to access these clinics and that the burden associated with the in-person visits is higher compared with those who live close to a specialised diabetes clinic. Reducing in-person visits frequency could be beneficial for these parents if their children's diabetes is well controlled. On the other hand, for those for whom diabetes was not controlled, reducing in-person visits could negatively affect their health. In a study in British Columbia, Canada, children travelling more than 2 hours to attend a tertiary T1D clinic had significantly higher mean glycated haemoglobin (HbA1C), increased perceived barriers to care, and lower satisfaction with treatment compared with those travelling less than 1 hour and those receiving care in their local community. ${ }^{31}$ In Amed et al, the proportion of person-years with an optimal or good adherence to clinical practice guidelines varied across health regions. ${ }^{18}$ This was explained by the fact that children and youth often travel long distances to access diabetes care.

Our findings suggest that a patient-centred approach with a flexible time interval between consecutive in-person clinic visits would be more efficient. Such an approach would enable a more efficient use of healthcare resources for T1D children and their parents and meet their needs. It is important to mention that we do not question the need for blood tests and frequent checks for HbA1c every 3 months as suggested by the current guidelines. We rather discuss: (1) the relevance of 3-month interval for in-person visits with the endocrinologist, which could be burdensome and unnecessary for some patients and (2) the need for more frequent visits than in the current guidelines for other patients. One could imagine more frequent in-person visits with the endocrinologist for children with poorly controlled $\mathrm{T}_{1} \mathrm{D}^{32}$ or those who are in a precarious situation. ${ }^{33}$ More frequent visits may also be required before the transition from paediatric to adult age, which is considered one of the most critical phases for adherence to treatment and T1D management. ${ }^{34}$ Some studies point out that the largest part of self-management transfer between parents and adolescents takes place when the patient is between the ages of 13 and $16 .{ }^{35}$ Less frequent 
in-person visits could be sufficient for children with well-controlled diabetes, those whose parents are able to make the necessary adjustments, or those benefiting from continuous or intermittent glucose monitoring and other diabetes-oriented technologies that facilitate remote monitoring.

There are some limitations to the study. First, a survey carries a self-selection bias that those choosing to participate may be different from people who abstain from participating. However, on observable characteristics, our sample seem to reflect the general population. Second, we had assumed that follow-up was always conducted with an endocrinologist. One respondent commented that in her remote area, follow-up visits were with a general practitioner as endocrinologists were not available. We consider that this occurrence should be rare and not have affected our results. Finally, we had limited information on the complexity of the diabetes. We did ask about whether HbAlc targets were reached, but this variable was not significant.

\section{CONCLUSION}

Overall, our study shows that there is heterogeneity in parent's preferences, with about 33\% of parents receiving what they perceived as too much care. A change in the protocols of visits with the endocrinologist could help direct resources where and when young patients with T1D and their parents will need them the most. More in-depth work must be undertaken in collaboration with healthcare providers and patients to determine how best to align visits with the needs and to ensure that burden on families is limited, yet that the follow-up is sufficient to ensure the health of children living with T1D. The approach could be extended to other chronic conditions to examine to which extent guidelines meet patients' needs, which could result in a shift of specialised healthcare resources between conditions for which there are unmet needs.

\section{Twitter Maude Laberge @MaudeLaberge}

Acknowledgements The authors are thankful to Dr. Malek Badreddine for providing her medical expertise in the project.

Contributors ML and MR designed the study, contributed to the data acquisition, analysis and interpretation. KMD contributed to the data analysis and interpretation. Each author wrote sections of the initial draft of the manuscript, critically revised the entirety of the manuscript and approved the final version. ML is responsible for the overall content as the guarantor.

Funding The project was funded with a grant from the Centre hospitalier universitaire de Québec-Université Laval.

Competing interests None declared.

Patient consent for publication Not applicable.

Ethics approval The first page of the survey contained information about the objective of the study and a statement that completing the survey was considered consent to the use of the collected data for research purposes. The study was approved by the Research Ethics Board of the CHU de Québec no 2017-3020 and was funded by the CHU de Québec-Université Laval, project number IS520664.

Provenance and peer review Not commissioned; externally peer reviewed.
Data availability statement No data are available. Data was collected in confidentiality and the ethics approval was only for use by the leading investigators.

Supplemental material This content has been supplied by the author(s). It has not been vetted by BMJ Publishing Group Limited (BMJ) and may not have been peer-reviewed. Any opinions or recommendations discussed are solely those of the author(s) and are not endorsed by BMJ. BMJ disclaims all liability and responsibility arising from any reliance placed on the content. Where the content includes any translated material, BMJ does not warrant the accuracy and reliability of the translations (including but not limited to local regulations, clinical guidelines, terminology, drug names and drug dosages), and is not responsible for any error and/or omissions arising from translation and adaptation or otherwise.

Open access This is an open access article distributed in accordance with the Creative Commons Attribution Non Commercial (CC BY-NC 4.0) license, which permits others to distribute, remix, adapt, build upon this work non-commercially, and license their derivative works on different terms, provided the original work is properly cited, appropriate credit is given, any changes made indicated, and the use is non-commercial. See: http://creativecommons.org/licenses/by-nc/4.0/.

ORCID iD

Maude Laberge http://orcid.org/0000-0003-1274-136X

\section{REFERENCES}

1 Heilporn G, Laberge M, Côté A, et al. From diagnosis to routine care in type 1 diabetes in children: Parents' experiences. Patient Exp $J$ 2019;6:42-9.

2 Zysberg L, Lang T. Supporting parents of children with type 1 diabetes mellitus: a literature review. Patient Intell 2015;7:21.

3 Delamater AM, de Wit M, McDarby V, et al. ISPAD clinical practice consensus guidelines 2018: psychological care of children and adolescents with type 1 diabetes. Pediatr Diabetes 2018;19 Suppl 27:237-49.

4 Nigam A. Changing health care quality paradigms: the rise of clinical guidelines and quality measures in American medicine. Soc Sci Med 2012;75:1933-7.

5 Legido-Quigley H, Panteli D, Brusamento S, et al. Clinical guidelines in the European Union: mapping the regulatory basis, development, quality control, implementation and evaluation across member states. Health Policy 2012;107:146-56.

6 Glikman J. The development process for clinical guidelines. Ann Med Psychol 2013;171:25-7.

7 Cosgrove L, Bursztajn HJ, Erlich DR, et al. Conflicts of interest and the quality of recommendations in clinical guidelines. J Eval Clin Pract 2013;19:674-81.

8 Jones DJ, Barkun AN, Lu Y, et al. Conflicts of interest ethics: silencing expertise in the development of international clinical practice guidelines. Ann Intern Med 2012;156:809.

9 Sale JEM, Marwah A, Naeem F, et al. Evidence of patient beliefs, values, and preferences is not provided in osteoporosis clinical practice guidelines. Osteoporos Int 2019;30:1325-37.

10 James PA, Cowan TM, Graham RP. Patient-Centered clinical decisions and their impact on physician adherence to clinical guidelines. J Fam Pract 1998;46:311.

11 Irwin B, Kimmick G, Altomare I, et al. Patient experience and attitudes toward addressing the cost of breast cancer care. Oncologist 2014;19:1135-40.

12 Blumenthal-Barby JS, Robinson E, Cantor SB, et al. The neglected topic: presentation of cost information in patient decision AIDS. Med Decis Making 2015;35:412-8.

13 Whittemore R, Jaser S, Chao A, et al. Psychological experience of parents of children with type 1 diabetes: a systematic mixed-studies review. Diabetes Educ 2012;38:562-79.

14 Harrington KR, Boyle CT, Miller KM. Management and family burdens endorsed by parents of youth. J Diabetes Sci Technol 2017;11:980-7.

15 Herbert LJ, Wall K, Monaghan M, et al. Parent employment and school/daycare decisions among parents of young children with type 1 diabetes. Child Health Care 2017;46:170-80.

16 Laberge M, Badreddine M, Rekik M. Online survey to assess parents experience and preferences for follow-up visits for children living with type 1 diabetes in Quebec, Canada: a study protocol. BMJ Open 2019;9:e031185.

17 Hatherly K, Overland J, Smith L, et al. Providing optimal service delivery for children and adolescents with type 1 diabetes: a systematic review. Pract Diab Int 2009;26:154-9. 
18 Amed S, Nuernberger K, McCrea P, et al. Adherence to clinical practice guidelines in the management of children, youth, and young adults with type 1 diabetes--a prospective population cohort study. $J$ Pediatr 2013;163:543-8.

19 Zucca A, Sanson-Fisher R, Waller A, et al. The first step in ensuring patient-centred quality of care: ask the patient. Eur J Cancer Care 2017;26:e12435

20 Montague T, Gogovor A, Aylen J, et al. Patient-centred care in Canada: key components and the path forward. Healthc $Q$ 2017;20:50-6.

21 Howe CJ, Ayala J, Dumser S, et al. Parental expectations in the care of their children and adolescents with diabetes. J Pediatr Nurs 2012;27:119-26.

22 Noser AE, Patton SR, Van Allen J, et al. Evaluating parents' selfefficacy for diabetes management in pediatric type 1 diabetes. $J$ Pediatr Psychol 2017;42:296-303.

23 Ginsburg KR, Howe CJ, Jawad AF, et al. Parents' perceptions of factors that affect successful diabetes management for their children. Pediatrics 2005;116:1095-104.

24 Chase HP, Pearson JA, Wightman C, et al. Modem transmission of glucose values reduces the costs and need for clinic visits. Diabetes Care 2003;26:1475-9.

25 Gandrud L, Altan A, Buzinec P, et al. Intensive remote monitoring versus conventional care in type 1 diabetes: a randomized controlled trial. Pediatr Diabetes 2018;19:1086-93.

$26 \mathrm{Xu} \mathrm{T,}$ Pujara S, Sutton S, et al. Telemedicine in the management of type 1 diabetes. Prev Chronic Dis 2018;15.
27 Yaron M, Sher B, Sorek D, et al. A randomized controlled trial comparing a telemedicine therapeutic intervention with routine care in adults with type 1 diabetes mellitus treated by insulin pumps. Acta Diabetol 2019:56:667-73.

28 Crossen S, Xing G, Hoch JS. Changing costs of type 1 diabetes care among US children and adolescents. Pediatr Diabetes 2020;21:644-8.

29 Davis V, Telang SB, Jain S, et al. Parental perception of the factors that affect diabetes management in youth. Clin Diabetes 2019;37:50-6.

30 Alsaleh FM, Smith FJ, Thompson R, et al. Insulin pump therapy: impact on the lives of children/young people with diabetes mellitus and their parents. Int J Clin Pharm 2014;36:1023-30.

31 Fox DA, Islam N, Amed S. Type 1 diabetes outcomes: does distance to clinic matter? Pediatr Diabetes 2018;19:1331-6.

32 Crossen S, Glaser N, Sauers-Ford H, et al. Home-Based video visits for pediatric patients with poorly controlled type 1 diabetes. $J$ Telemed Telecare 2020;26:19828173.

33 Walker AF, Haller MJ, Gurka MJ, et al. Addressing health disparities in type 1 diabetes through peer mentorship. Pediatr Diabetes 2020;21:120-7.

34 Spaans EAJM, Kleefstra N, Groenier KH, et al. Adherence to insulin pump treatment declines with increasing age in adolescents with type 1 diabetes mellitus. Acta Paediatr 2020;109:134-9.

35 Keough L, Sullivan-Bolyai S, Crawford S, et al. Self-Management of type 1 diabetes across adolescence. Diabetes Educ 2011;37:486-500. 